\title{
Differential Response of Cylindrospermum musicola, Calothrix javanica and Westiellopsis prolifica to Endotaf (Endosulfan, 35\%), an Organochlorine Pesticide
}

\author{
G. S. Shinde
}

K. J. Somaiya College of Arts, Commerce and Science, Kopargaon, Dist. Ahmednagar, Maharashtra, India

Article Info

Volume 8 Issue 2

Page Number : 406-411

Publication Issue :

March-April-2021

\section{Article History}

Accepted : 15 April 2021

Published : 30 April 2021

\section{ABSTRACT}

The effect of Endotaf (Endosulfan, 35\%) pesticide was studied on nitrogen fixation efficiency of Cylindrospermum musicola, Calothrix javanica and Westiellopsis prolifica at different concentrations of pesticide in the nitrogen free BG-11 medium. Total nitrogen fixed by blue-green algal species was estimated by conventional Micro- kjeldahl method in the laboratory cultures at each concentration of Endotaf pesticide. The results obtained during the present investigation indicated a progressive decrease in the total nitrogen content of the tested blue-green algae with increasing concentrations of the Endotaf pesticide. However, nitrogen fixation of most of the blue-green algae was also increased at the lower doses of pesticide. The consequences of the results revealed that Calothrix javanica was emerged as most compatible and tolerant to the increasing Endotaf pesticide doses than the other tested blue-green algal species. On the other hand, Cylindrospermum musicola was found to be highly susceptible as even at $2.5 \mathrm{ppm}$ of Endotaf. Calothrix species was capable to tolerate upto $10 \mathrm{ppm}$ of Endotaf while in Westiellopsis prolifica and Cylindrospermum musicola, the pesticide tolerance range was found to be upto $5 \mathrm{ppm}$ and $2.5 \mathrm{ppm}$ with Endotaf, respectively. Further increase in pesticides concentrations a gradual decline in the total nitrogen content occurred in all the tested blue-green algal strains. It is concluded that indiscriminate use of these pesticides may cause adverse effects on the nitrogen fixing blue-green algae of various crop fields, which has a direct influence on total productivity. Since it is essential to screen efficient blue-green algal strains those are capable of growing and fixing nitrogen at higher rate even in presence of recommended doses of the agrochemicals including pesticides, before their inoculation into the field.

Keywords: Endotaf (Endosulfan, 35\%), Total nitrogen, Cylindrospermum musicola, Calothrix javanica and Westiellopsis prolifica

\section{INTRODUCTION}

Agriculture in India is the largest sector of economic activity and has a crucial role to play in the country's economic development in various ways. Since 1970, agricultural development has been changed from traditional farming methods to more modern intensive practices using chemical fertilizers, 
pesticides and irrigation facilities. The present day global interest in biological nitrogen fixation is a direct consequence of biofertilizer particularly bluegreen algae. It has been proved as the most efficient source of organic nitrogen [1]. These eco-friendly biofertilizers enhance soil health and make a significant contribution towards the sustainable agriculture development [2].

Most of the heterocystous and non-heterocystous blue-green algae are known to fix nitrogen. The most common nitrogen fixing species belongs to genera like Nostoc, Aulosira, Anabaena, Calothrix, Cylindrospermum, Microchaete, Scytonema, Tolypothrix, Fischerella, Hapalosiphon etc. It has been reported that the part of nitrogen requirements for the crops (25- $35 \%$ ) could be met by algalisation under different agroclimatic conditions [3]. Reduction of chemical fertilizers input upto $30 \%$ by supplementing with blue-green algae as a significant finding when conservation of energy is contemplated. In agriculture, introduction of fertilizer responsive crop varieties has demanded the use of huge amounts of pesticides during production and storage. The varied range of pesticides like organochlorines, organophosphates, carbamates and synthetic pyrethroids are now in use. Many chlorinated and organophosphorus pesticides, which are not readily soluble in water, are emulsified [4]. This affinity results in their accumulation through adsorption on to the surface of living organisms [5]. These agrochemicals also damage wide variety of beneficial microorganisms particularly blue-green algae because of their long persistence in the environment [6]. By considering this issue the present investigation is planned to study the differential response of Cylindrospermum musicola, Calothrix javanica and Westiellopsis prolifica to Endotaf (Endosulfan, 35\%) pesticide in the laboratory cultures.

\section{METHODS AND MATERIAL}

The effect of Endotaf pesticide was studied on nitrogen fixation efficiency of Cylindrospermum musicola, Calothrix javanica and Westiellopsis prolifica in experiments with $2.5,5,10,20,50,100$, 250 and 500 ppm concentrations of Endotaf pesticide in the $50 \mathrm{ml}$ of nitrogen free BG-11 medium [7]. Total nitrogen fixed by blue-green algal species was estimated by conventional Micro- kjeldahl method [8] in the laboratory cultures after 28 days of harvesting at each concentration of Endotaf pesticide. Experiments were conducted by inoculating equal amounts of actively growing unialgal isolates into cotton stoppered conical flasks.

Commercial grade pesticide as organochlorine, Endotaf (endosulfan, 35\%) belonging to organochlorine group is used to control sucking, lepidopterous and nematode pests and mites that occurred in maize, wheat, sugarcane, cotton, onion, vegetable and oil yielding crops. Endotaf attacks on central nervous system and make interference in $\alpha$ amino butyric acid receptor activity of the pest. The pesticide application rates recommended to control various crop pests of this region are 0.5 liter/ha for Endotaf (endosulfan, 35\%) and which will provide a range of 2.5- $5 \mathrm{ppm}$ in the crop field.

\section{III.RESULTS AND DISCUSSION}

The practical results regarding total nitrogen (\%) fixed by soil blue-green algae in the laboratory cultures are depicted in the Table- 1 and graphically represented in the Fig. 1. The consequences of the pragmatic results revealed that, the blue-green alga Calothrix javanica were emerged as most compatible and tolerant to the increasing pesticides doses as compared to the other tested blue-green algae. To the contrary, Cylindrospermum musicola was found to be the highly susceptible as even at $2.5 \mathrm{ppm}$ of Endotaf. At this concentration, $29.75 \%$ reduction in total 
nitrogen content was recorded with Endotaf pesticide in the Cylindrospermum musicola. This is supported by [9] who concluded that, Cylindropermum sp. appears to affect severely by the Benzene Hexachloride, Lindane, Diazinon and Endrin pesticides.

Table 1: Total nitrogen (\%) fixed by Soil Blue-green algal species at different concentrations of Endotaf pesticide in laboratory cultures (Harvested after 28 days of incubation)

\begin{tabular}{|c|c|c|c|}
\hline \multirow{2}{*}{$\begin{array}{l}\text { Conc. } \\
\text { of } \\
\text { Endotaf } \\
\text { pesticid } \\
\text { e (ppm) }\end{array}$} & \multicolumn{3}{|c|}{ Total Nitrogen (\%) Fixed } \\
\hline & $\begin{array}{c}\text { Cylindrospermu } \\
\text { m musicola }\end{array}$ & $\begin{array}{c}\text { Calothri } \\
x \\
\text { javanica }\end{array}$ & $\begin{array}{c}\text { Westiellopsi } \\
\text { s prolifica }\end{array}$ \\
\hline $\begin{array}{l}0.00 \\
\text { (Control } \\
\text { ) }\end{array}$ & 4.6 & 5.1 & 4.7 \\
\hline 2.5 & $4.74(+2.1)$ & $\begin{array}{c}5.24 \\
(+1.7)\end{array}$ & $4.88(+3.8)$ \\
\hline 5 & $3.26(-29.7)$ & $\begin{array}{c}5.41 \\
(+5.0)\end{array}$ & $4.76(+1.7)$ \\
\hline 10 & $2.42(-47.8)$ & $\begin{array}{c}5.00(- \\
2.9)\end{array}$ & $3.58(-23.8)$ \\
\hline 20 & $1.92(-58.6)$ & $\begin{array}{c}4.32(- \\
16.1)\end{array}$ & $2.18(-53.6)$ \\
\hline 50 & $1.00(-78.4)$ & $\begin{array}{c}3.56(- \\
30.8)\end{array}$ & $1.34(-71.4)$ \\
\hline 100 & $0.20(-95.6)$ & $\begin{array}{c}2.10(- \\
59.2)\end{array}$ & $0.30(-93.6)$ \\
\hline 250 & -- & $\begin{array}{c}1.27(- \\
75.3)\end{array}$ & -- \\
\hline 500 & -- & $\begin{array}{c}0.24(- \\
95.3)\end{array}$ & -- \\
\hline
\end{tabular}

Values represents mean of three replicates; figures in parenthesis show percent increase $(+)$ or decrease $(-)$ as compared to total nitrogen content (\%) in the untreated control.

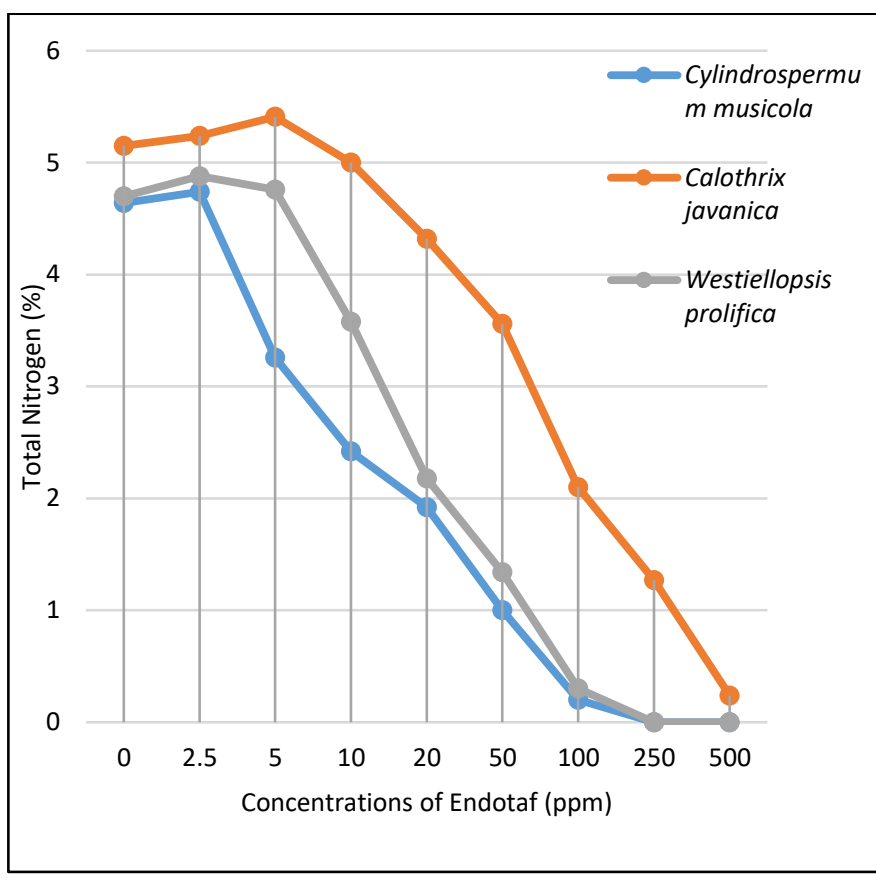

Fig. 1 : Total nitrogen (\%) fixed by Soil Blue-green algal species in presence of Endotaf pesticide

The enhancement in total nitrogen content was observed in the Westiellopsis prolifica upto $5 \mathrm{ppm}$ dose level and in Cylindrospermum musicola at 2.5 ppm with Endotaf pesticide than the untreated control. Although, with Endotaf, nitrogen fixation by Westiellopsis prolifica was consistently decrease at 10 ppm concentration, while in Cylindrospermum musicola the pesticide concentration recorded was 5 ppm where decrease in total nitrogen content was observed over the control. Moreover, at $100 \mathrm{ppm}$ dose level of Endotaf, total nitrogen content was decreased by $93.6 \%$ in Westiellopsis prolifica and $95.6 \%$ in Cylindrospermum musicola than the control. Further increase in pesticides concentration resulted into ceasing of growth and nitrogen fixation in both the tested blue-green algae. (Table- 1 and Fig.1)

To the contrary, Calothrix javanica was found to be more tolerant and compatible to the Endotaf pesticide dosage than the other tested blue-green algae. In the presence of Endotaf, it showed increased nitrogen fixation upto $5 \mathrm{ppm}$ concentration as compared to the untreated control. Furthermore, total nitrogen content was consistently decreased with the increasing concentrations of pesticides over the 
control from $10 \mathrm{ppm}$ of Endotaf. At the higher concentration i.e. $500 \mathrm{ppm}$ with Endotaf, 95.3\% reduction in total nitrogen content was recorded in Calothrix javanica than the untreated control. (Table1 and Fig. 1)

In general, tolerance and compatibility regarding nitrogen fixation exhibited by the tested blue-green algae to the organochlorine pesticide, Endotaf was found in the order of-

\section{Cylindrospermum musicola $>$ Westiellopsis prolifica > Calothrix javanica}

The mechanism of tolerance of Calothrix javanica to the Endotaf pesticide is possibly due to the presence of sheath outside the cell wall of these algae, which might be protecting it from the adverse effect of the toxic chemicals.

The reduction in total nitrogen content of the pesticide-adapted blue-green algal strains may be occurred due to the inhibition of some stage(s) during the process of nitrogen fixation in the presence of higher concentrations of pesticides. Further stimulatory effect of Endotaf at lower concentrations on nitrogen fixation of blue-green algae under culture conditions may be due to the presence of nutrients in media that minimizes the toxicity of pesticide [10, 11]. [12] reported a stimulatory effect on nitrogen fixation in most studied blue-green algal forms while a general pattern of gradual decline occurred with increasing dose level of eight widely hitherto used pesticides. Increased nitrogen fixation in the presence of pesticide doses of Furadan [13], 2,4- D [14] and Sevin [15], Rogor [16], Endosulfan, [17] by the bluegreen algae was noted by earlier workers.

Similarly, [18] and [19] described lower concentrations of the pesticides Rogor, Dithane M-45, and 2,4- D sodium salt in pure culture favoured nitrogen fixation by the isolates of Anabaena variabilis, Calothrix sp., Cylindrospermum musicola, Hapalosiphon welwitschii, Nostoc sp. whereas higher concentrations gave an adverse effect. [20], found that Endosulfan at $12 \mathrm{ppm}$ proved lethal for Anabaena sp. while extreme fragmentation and subsequent death occurred in Spirulina platensis at $8 \mathrm{ppm}$. [21] observed that lower concentrations of Monocrotophos and Butachlor caused stimulation of growth and nitrogen fixation and partial or complete inhibition occurred at higher concentrations in Anabaena sp. and Westiellopsis prolifica. [22] revealed that, nitrogen fixation in Nostoc and Anabaena isolates was increased after the application of Furadan at concentration up to $50 \mathrm{ppm}$. The bluegreen algal isolates were more tolerant to Furadan and the effects of Furadan were stimulatory at field dose on the growth and nitrogen fixation. [23] informed a pesticide concentration dependent reduction in the nitrogen content of Anabaena variabilis, Nostoc muscorum, Calothrix parietina and Westiellopsis prolifica with organophosphate pesticide, Rogor.

\section{CONCLUSION}

The practical results obtained during the present investigation revealed that in laboratory cultures, Endotaf pesticide was found to be highly toxic to all the tested blue-green algae. A progressive decline in the nitrogen fixation of tested blue-green algae occurs with increasing concentrations of pesticide. However, Calothrix javanica was found to be more tolerant to the increasing pesticides doses than the Cylindrospermum musicola and Westiellopsis prolifica. In general, it was seen that even $10 \mathrm{ppm}$ of Endotaf pesticide application adversely affected the occurrence and survivability of studied blue-green algae in the laboratory culture which are responsible for nitrogen fixation. This suggest that indiscriminate use of these pesticides may cause adverse effects on the nitrogen fixing blue-green algae of various crop fields, which has a direct influence on total productivity.

Since nitrogen fixing blue-green algae are now used as biofertilizer, it is essential to screen efficient BGA strains those are capable of growing and fixing nitrogen at higher rate even in presence of recommended doses of the agrochemicals including 
pesticides, before their inoculation into the field. The blue-green algal species possessing a well- defined sheath layer outside their wall are the promising strains which can thrive in the pesticide burdened soils and also continue to grow and fix nitrogen in the presence of relatively higher pesticides doses than the sheathless strains. Thus, these can be included in the multi- strain mixture for using as biofertilizer.

\section{REFERENCES}

[1]. Ahmed, S. U. 2001. Nitrogen fixing potential of cyanobacteria isolated from rice field soils of Nagaon sub- division Assam. Phykos, 40 (1 and 2): 53- 59 .

[2]. Swaminathan, M. S. 2007. Agricultural renewal and prosperity. Yojana, 51 (1): 89- 90.

[3]. Rai, A. N., Soderback, E. and Bergman, B. 2000. Tensley review: Cyanobacterium plant symbiosis. New phytologist, 147: 449- 481.

[4]. Kapoor K. and Arora L. 2000. Comparative studies on the effect of pesticides on nitrogenfixing Cylindrospermum majus Kutz. ex Born. et Flah. Indian J. Environ Sci., 4 (1): 89- 96.

[5]. Rajendran, U.M., Kathirvel, E. and Narayanaswamy, A. 2006. Effects of a fungicide, an insecticide, and a biopesticide on Tolypothrix scytonemoides. Center for Advanced Studies in Botany, University of Madras, Chennai, India.

[6]. Islam, M. Z., Begum, S., Ara, H. and Waliullah, T. M. 2007. Effect of furadan on the growth and nitrogen fixation by blue green algae. J. Bio-sci., 15: 23- 35.

[7]. Rippka, R., Derulles, J., Waterburry, J., Herdman, M. and Stanier, R. 1979. Genetic assessments, strain histories and properties of pure cultures of Cyanobacteria. J. Gen. Microbiol. 111: 1- 61.

[8]. Jackson, M. 1958. Soil chemical analysis. Pub. Prentice Hall, Engelwood Cliffs, New Jersey, O.S.A.P. 183.
[9]. Singh, P. K. 1973. Effects of pesticide on blue green algae. Arch Mikrobiol. 89: 317-320.

[10]. Kar, S and Singh, P. K. 1978a. Toxicity of carbofuran to blue-green alga Nostoc muscorum. Bull Environ. Contam. Toxicol., 20 (5): 707- 714.

[11]. Sharma, V. K. and Gaur, Y. S. 1981. Nitrogen fixation by pesticide-adapted strains of paddy field cyanophytes. Intl. J. Ecol. Env. Sci., 7: 117122.

[12]. DaSilva, E. J., Henriksson, L. E. and Henriksson, E. 1975. Effect of pesticides on blue-green algae and nitrogen fixation. Arch. Environ. Contam. Toxicol., 3: 193- 204.

[13]. Kar, S. and Singh, P. K. 1978b. Effect of pH, light intensity and population on the toxicity of the pesticide carbofuran to the blue- green alga Nostoc muscorum and Wollea bharadwajae. Microb. Lett., 10: 177- 184.

[14]. Das, B. and Singh, P. K. 1977. Detoxication of the pesticide benzenehexachloride by bluegreen algae. Microbios Lett., 4: 99- 102.

[15]. Adhikary, S. P., Dash, P. and Pattnaik, H. 1984. Effect of the carbamate insecticide Sevin on Anabaena sp. and Westiellopsis prolifica. Acta Microbiol., 31 (4): 335- 338.

[16]. Pattnaik, H. and Prakash Rao, M. 1982. Effect of pesticides on growth and nitrogen fixation of blue-green algae. In Proceedings of a National Symposium on Biological Nitrogen Fixation, New Delhi. Page 670.

[17]. Adhikary, S. P. 1989. Effect of pesticides on the growth, photosynthetic oxygen evolution and nitrogen fixation of Westiellopsis prolifica. J. Gen. Appl. Microbiol., 35 (4): 319- 326.

[18]. Shivaprakasha, M. K. and Shivappa Shetty, K. 1986. Effect of three common agricultural chemicals on growth and nitrogen fixation by blue-green algae. J. Soil. Biol. Ecol., 6: 16- 23.

[19]. Shivaram, S. and Shivappa Shetty, K. 1988. Studies on the effect of pesticides on the growth 
and nitrogen fixation by blue-green algae. Mysore J. Agric. Sci. 22: 222- 225.

[20]. Satyendra Kumar, Jetley, U. K. and Tanseem Fatma. 2000. Tolerance of Spirulina platensis and Anabaena sp. to endosulfan, an organochlorine pesticide. Annals of Plant Physiology, 17 (5): 45- 52.

[21]. Kiran, Sharma, S. G. and Singh, S. P. 2006. Effect of monocrotophos and butachlor on $\mathrm{N}$ fixing cyanobacteria and associated biochemical activities. Annals of Plant Protection Sciences, 14 (1): 78- 85.

[22]. Islam, M. Z., Begum, S., Ara, H. and Waliullah, T. M. 2007. Effect of furadan on the growth and nitrogen fixation by blue green algae. J. Bio-sci., 15: 23- 35 .

[23]. Das, M. K. 2008. Differential response of cyanobacteria to an organo-phosphate pesticide, rogor (dimethoate $30 \mathrm{Ec}$ ). Nature Environment and pollution technology, 7 (1): 55- 61.

\section{Cite this article as :}

G. S. Shinde, "Differential Response of Cylindrospermum musicola, Calothrix javanica and Westiellopsis prolifica to Endotaf (Endosulfan, 35\%), an Organochlorine Pesticide", International Journal of Scientific Research in Science, Engineering and Technology (IJSRSET), Online ISSN : 2394-4099, Print ISSN : 2395-1990, Volume 8 Issue 2, pp. 406-411, March-April 2021. Available at doi : https://doi.org/10.32628/IJSRSET218296

Journal URL : https://ijsrset.com/IJSRSET218296 